\title{
US Congress hears the good news on Chinese food
}

Washington

A US congressional hearing is not usually the place to hear the latest scientific results. But last week, those attending the Senate Committee on Governmental Affairs had a preview of a massive study on the relationship between diet and disease carried out in China by Cornell University, the University of Oxford and the Chinese Academies of Preventive Medicine and Medical Sciences.

From the highlights presented by $\mathrm{T}$. Colin Campbell, professor of nutritional biochemistry at Cornell University, the Chinese study seeems likely to provide a massive database for testing the relationships between diet and disease and to affect significantly the nutritional advice given to Westerners.

The Senate committee was taking evidence on "Nutrition in Health and Disease" with the aim of clarifying "the confusion spawned by the proliferation of dietary advice" and finding a more effective federal government role in nutrition research. The first-ever Surgeon-General's report on nutrition and disease will be released this summer.

Campbell's view is that nutritional advice has been too fragmented. Recommendations have focused on single nutrients without a wider perspective that takes into account the enormous complexity of biological relations.

The only way to sort out the complex interactions of diet, disease and human variation is through examination of large cohorts of people, with stable but diverse eating habits. China is perhaps the only country in the world where this can be easily done. Rural Chinese people usually remain in one area all their life, eating the same kinds of local foods. Incidence of disease and dietary habits vary enormously. In contrast, the mobile populations of the west have become more uniform.

China also has the organizational capacity to carry out large-scale surveys and an epidemiological tradition to live up to. In the 1970 s, a massive epidemiologial survey was carried out that resulted in the now famous Atlas of Cancer Mortality in the People's Republic of China (Nature 318, $218 ; 1985)$. The survey charted striking differences in the incidence of various cancers in different regions of the country.

That atlas forms the base for the new survey linking diet and disease. Sixty-four counties, selected for their extreme variation in diet and in mortality characteristics, were revisited by Chinese teams. Over a five-year period, blood and samples and information on lifestyles were collected from 6,500 people in 130 villages. Half of the 6,500 also provided urine samples and day-by-day details of their diet. Food samples were taken away for analysis. Altogether, the teams put in some 600 man-years of professional labour.

Specimens then went out to laboratories around the world. Data were assembled on hormone, mineral and fat levels; on the incidence of virus antibodies; on dietary composition; on individual health and many other factors. A total of some 350 variables were recorded.

The results are now sitting in a computer at the laboratory of epidemiologist Richard Peto at the University of Oxford. Through the generosity of the Chinese, whose efforts Campbell estimates would have cost "more than $\$ 100$ million" in the United States, the world's researchers will be given free access to the databank later this year.

A few nuggets have already been mined from the data. One surprise is that Chinese people consume about 20 per cent more calories than Americans. But there is very little obesity among the Chinese, showing that calories alone do not cause excess weight and are unlikely to determine chronic disease. The Chinese do not eat much fat: on average, fats make up only
15 per cent of calorific input, less than half the amount usually recommended in the United States. But the low fat intake does not seem to produce any ill-effects.

Chinese people have serum cholesterol levels that are so low that they are almost off the bottom of the scale for the US population. Cardiovascular disease is correspondingly low, as expected, but worries raised by US data showing an increased risk of colon cancer at very low serum cholesterol levels appear groundless.

The Chinese diet is also full of fibre: average intake is 34 grams a day, more than three times the US average but close to the amount recommended by the National Cancer Institute. Fears that high-fibre diets could hamper mineral uptake are not substantiated. Plasma, iron, zinc and magnesium are all at healthy levels.

Although the Chinese study is the biggest collection of diet and disease data yet put together, it is still small compared with what Campbell has planned. Additional surveys will soon add more detailed mortality statistics for the areas where the diet-disease survey was conducted. In 1989 , a supplementary survey will be launched. And beyond that, a prospective study of 525,000 individuals is being planned. That should provide data to keep researchers busy for the next 50 years.

Alun Anderson

\section{Brighter travel prospects for Hungary's hard-up scientists}

London

RECENT cuts in the Hungarian science budget and the new relaxed passport laws could lead to more Hungarian scientists taking jobs abroad. Since 1 January, every Hungarian citizen has an automatic right to a passport, although to travel to the West, an appropriate amount of hard currency is also necessary. Although there seems no immediate likelihood of a brain drain, there will almost certainly be a significant increase in dependence on the facilities of foreign laboratories to do experimental work, a feature of Hungarian scientific life in recent years.

Scientific exchanges and visits are recognized as a stimulus to scientific success. But many of the Hungarian scientists who make the greatest use of Western facilities are embarrassed that such visits give access to apparatus Hungary cannot afford to buy.

Last July's reform budget considerably exacerbated the situation. The central budgetary support for science was cut by some 15 per cent over 1987-88, but taking inflation into account, the real drop in funding will be about 30 per cent.

Dr Ivan T. Berend, president of the Hungarian Academy of Sciences, has expressed a fear that some academy insti- tutes and academy-supported university research would have to close has so far not materialized, partly due to the former system of centralized economic management. Under this now discredited system, there was a sharp line of demarcation between research and development institutes and manufacturing enterprises. Although for some years in-house research has been permitted and even encouraged, Hungarian industry has, by no means, taken over responsibility for the research and development base, and, as the available central funding has fallen off, research institutes have secured more and more direct research and development contracts from industry and have even begun running small production projects on their own account.

But the resources and demands of Hungarian industry are finite, and it is particularly difficult for basic research to secure appropriate contracts from the industrial sector. Fortunately, the 4,000 million forints one-off emergency injection of support for basic research which the government authorized in 1986 has not been affected by the cuts and will, in the short term, help to cushion the effects of the recession. But the long-term prospects are less bright.
Vera Rich 